\title{
The Effects of Response Readiness and Error Monitoring on Saccade Countermanding
}

\author{
Yuan-Chi Tseng ${ }^{1,2}$ and Chiang-Shan Ray $\mathrm{Li}^{1,3, *}$ \\ ${ }^{1}$ Medical Research Center, Chang Gung Memorial Hospital, Tao-yuan, Taiwan; ${ }^{2}$ Interaction, Cognition and Decision, \\ Manchester Business School, The University of Manchester, Manchester, UK and ${ }^{3}$ Department of Psychiatry, Yale Uni- \\ versity, New Haven, CT, USA
}

\begin{abstract}
The stop-signal task (SST) and anti-saccade tasks are both widely used to explore cognitive inhibitory control. Our previous work on a manual SST showed that subjects' readiness to respond to the go signal and the extent to which subjects monitor their errors need to be considered in order to attribute impaired performance to deficits in response inhibition. Here we examine whether these same task-related variables similarly influence oculomotor SST and anti-saccade performance. Thirty-six and sixty healthy, adult subjects participated in an oculomotor SST and anti-saccade task, respectively, in which the fore-period (FP) of imperative stimulus varied randomly from trial to trial. We computed a FP effect to index response readiness to the imperative stimulus and a post-error slowing (PES) effect to index error monitoring. Contrary to what we had anticipated, other than a weak but negative association between the FP effect and anti-saccade errors, these behavioral variables did not correlate with SST or anti-saccade performance.
\end{abstract}

Key Words: Stop-signal, go/no-go, impulsivity, inhibitory function, frontal, oculomotor.

\section{INTRODUCTION}

The saccade countermanding tasks - including the oculomotor stop signal task (SST) and anti-saccade task - are widely used to explore executive control functions [1-5]. In an anti-saccade task, there are pro-saccade trials, in which subjects make a visually guided saccadic eye movement toward to a peripheral target, and anti-saccade trials, in which subjects make an eye movement in the opposite direction. In order to execute an anti-saccade, one has to inhibit the reflexive tendency to make a pro-saccade elicited by the peripheral target, and engage the oculomotor machinery to make an eye movement in the desired direction. Occasionally one fails to override the tendency to make a pro-saccade in an anti-saccade trial, resulting in a "directional" error [6]. When one does make an anti-saccade, the RT of the antisaccade is increased, compared to a pro-saccade, as a result of additional processing during visuomotor transformation in which inhibitory control assumes a critical role. An index of inhibitory control function can thus be derived based on the error rate and RT increase of anti-saccade trials. Because these outcome measures are clearly defined, the anti-saccade task is well suited for exploring the neural mechanism of response inhibition and behavioral impulsivity in patients with neurological or psychiatric conditions. For instance, studies in humans with brain lesions have implicated the prefrontal cortex during impaired anti-saccade performance [7-9].

The SST is another behavioral task widely used to explore inhibitory control [10]. There are two types of trials in

\footnotetext{
*Address correspondence to this author at the Department of Psychiatry, Yale University, Connecticut Mental Health Center S103, 34 Park Street, New Haven CT 06519, USA; Tel: 203-974-7354; Fax: 203-974-7366; E-mail: chiang-shan.li@yale.edu
}

the SST. In go trials, subjects respond to a go signal generally as quickly as possible; in stop trials, a stop signal follows the go signal and instructs subjects to withhold the response. There are more go trials than stop trials, so a prepotent response tendency (a "habit") is set up and the processes "countering" this tendency can be examined in the SST. The ease with which one can withhold a response depends on the time interval between the go and stop signals, or the stop-signal delay (SSD): the longer the SSD the more difficult it is for one to stop and vice versa. One way to characterize response inhibition is by way of the stop signal reaction time (SSRT), which describes how long it takes for the stop-signal to be processed so a response can be withheld [11]. For instance, with a staircase procedure, in which the SSD decreases by a specified step to make it easier for the subject to stop at the stop signal if the subject fails at a previous stop trial and increases by the same step if the subject succeeds, one can achieve a success rate of approximately $50 \%$ in the stop trials. A "critical" SSD can then be computed that represents the time delay required for the subject to succeed in the stop trials half of the times [12]. The stop signal reaction time (SSRT) is then estimated by subtracting the "critical" SSD from the median reaction time (RT) of the go trials $[10,11]$. The SST is widely used as a cognitive proxy to describe response inhibition in people with neurological or psychiatric conditions, including patients with substance use disorders [13-24]. These patients invariably were found to have prolonged SSRT, compared to healthy control subjects.

However, cognitive processes other than response inhibition can influence performance in the anti-saccade task or the SST. A major goal of experimental psychology is to dissect these processes so impaired task performance can be attributed to their proper sources. For instance, we previously 
used a manual SST with the afore-described tracking procedure to examine response inhibition both in cocaine dependent and Tourette Disorder patients and in healthy individuals [17, 25-27]. We observed that two task-related variables could influence stop signal performance. We computed a fore-period (FP) effect as a measure of response readiness to the go signal and a post-error slowing (PES) effect as a measure of performance monitoring during the task. The FP effect described how go trials reaction time (RT) decreased with increased duration of preparation during the FP and the PES effect showed how much one slowed down in response to the go trials following a stop error [28-30]. We found that the FP effect correlated positively with SSRT and the PES effect correlated negatively with SSRT in linear regression [25-27]. These results indicate that performance strategy in terms of selectively attending to the go signal (i.e., the FP effect) or the stop signal (i.e., the PES effect) can influence stop signal performance. We suggested that these variables need to be accounted for in order to attribute stop signal performance to response inhibition.

In this study we hypothesized that these same considerations apply to oculomotor SST and anti-saccade task, both of which involve motor preparation and error monitoring [2, 31-33]. We made two specific predictions. First, in the oculomotor SST, the SSRT correlates positively with the FP effect and inversely with the PES effect. Second, in the antisaccade task, the error rate and RT increase of the antisaccade trials correlate positively with the FP effect and inversely with the PES effect. More broadly, confirmation of these hypotheses would provide further evidence that motor preparation and error monitoring are important cognitive variables that may influence performance in a wide range of neuropsychological tasks.

\section{METHODS}

\section{Subjects and General Experimental Condition}

A total of 101 college students (18 to 27 years of age) were paid to participate in the study. Forty of them (18 women and 22 men) took part in the saccade countermanding task and the other 61 ( 35 women and 26 men) in the antisaccade task. All of them had normal or corrected-to-normal vision. No formal psychiatric interview or medical exams were performed but they all denied ever having a neurological or psychiatric condition or using an illicit substance. All subjects consented after given a detailed description of the study, in accordance to institute guidelines. Studies were conducted in an office dimly lit, mostly in the evening or over the weekend where it was quiet and free of interruptions. Subjects sat in front of a PC monitor approximately 57 $\mathrm{cm}$ away with their chin supported by a chin rest. Eye position was monitored by an infra-red system (EyeLink®II, SR Research Ltd., Mississauga, Ontario, Canada) at a spatial resolution of $0.1^{\circ}$ (of visual angle) and $500 \mathrm{~Hz}$, and corrected for head movement. The set up was calibrated for each individual subject before the study. Saccadic eye movements were defined to have a minimum velocity of $30 \% \mathrm{~s}$ and $\mathrm{mi}-$ nimum acceleration of $9,500 \% \mathrm{~s}^{2}$. The onset of a saccade was defined as the time when the eye movement velocity exceeded $30 \%$ s. Our previous work showed that these criteria were useful in capturing the dynamics of saccadic eye movements under the same setup [34].

\section{Oculomotor SST}

Fig. (1a) illustrates the task. The oculomotor SST consisted of 270 "go" and 90 "stop" trials, randomly intermixed in an experiment. In a go trial, a fixation point ( $1^{\circ}$ across) appeared at the center of the screen to engage attention and eye fixation. The subjects were instructed to press a control button to initiate each trial whenever they felt they have acquired the center fixation. The trial would start only if the subject had maintained fixation within the center square. The fixation point extinguished following a randomized foreperiod (FP) between 0.5 and $1.5 \mathrm{sec}$ (selected from a uniform distribution), and a target (the "go" signal) appeared at a peripheral location, $6^{\circ}$ to the left or right. The subjects were to make a saccadic eye movement to the target. The trial terminated after the target was acquired or after $750 \mathrm{~ms}$ elapsed, whichever came first. A premature saccade also terminated the trial and counted as a fixation error. In a stop trial, the center fixation (the "stop" signal) re-appeared after the onset of the peripheral target, instructing the subjects to maintain fixation at the center square. They had to maintain fixation for at least $750 \mathrm{~ms}$ for the trial to be considered as a success. The time delay between the go and the stop signal or the stop-signal delay (SSD) varied from trial to trial (irrespective of target location) following a staircase procedure; if the subjects failed in a previous stop trial, the SSD decreased by $40 \mathrm{~ms}$ and, conversely, if the subjects succeeded in a previous stop trial, the SSD increased by $40 \mathrm{~ms}$. With the staircase procedure, we anticipated that most subjects would succeed in maintaining their eye fixation at the center location in approximately $50 \%$ of the stop trials. Subjects who made an excessive number of fixation failures during the FP or achieved a success rate less than $95 \%$ in the go trials or more than $55 \%$ or less than $45 \%$ of stop trials were considered as not following the instructions and excluded from further analysis. Most subjects completed the task within 40 minutes.

\section{Anti-Saccade Task}

Fig. (1b) illustrates the task. The anti-saccade task consisted of 270 pro-saccade and 90 anti-saccade trials, randomly intermixed in an experiment. A light point subtending $1^{\mathrm{o}}$ in diameter appeared at the center of the screen to begin a trial. The subject was instructed to fixate the center light stimulus and press a control button to initiate a trial whenever they have acquired the target. The trial started only if the subject had maintained fixation within the center square. After the FP or a randomized time interval between 0.5 and $2.0 \mathrm{sec}$ following successful fixation, a target appeared in one of the two square boxes (approximately $2^{\circ} \times 2^{\circ}$ ) located at $6^{\circ}$ to the right and left of the center fixation. In a prosaccade trial, the target was a disk ( $2^{\circ}$ across), signaling the subject to make a visually guided eye movement to the target. The subject had to initiate a saccade within $750 \mathrm{~ms}$ or the trial was aborted. In an anti-saccade trial, the target was an "X", signaling the subject to make an eye movement toward the box across. The subjects had to initiate the antisaccade within $1,500 \mathrm{~ms}$. If subjects made a fixation error or an error in the pro-saccade or anti-saccade trials, a new trial would be inserted at the end of the "stack." Most subjects completed the task within 45 minutes. 


\section{(a) saccade countermanding task}

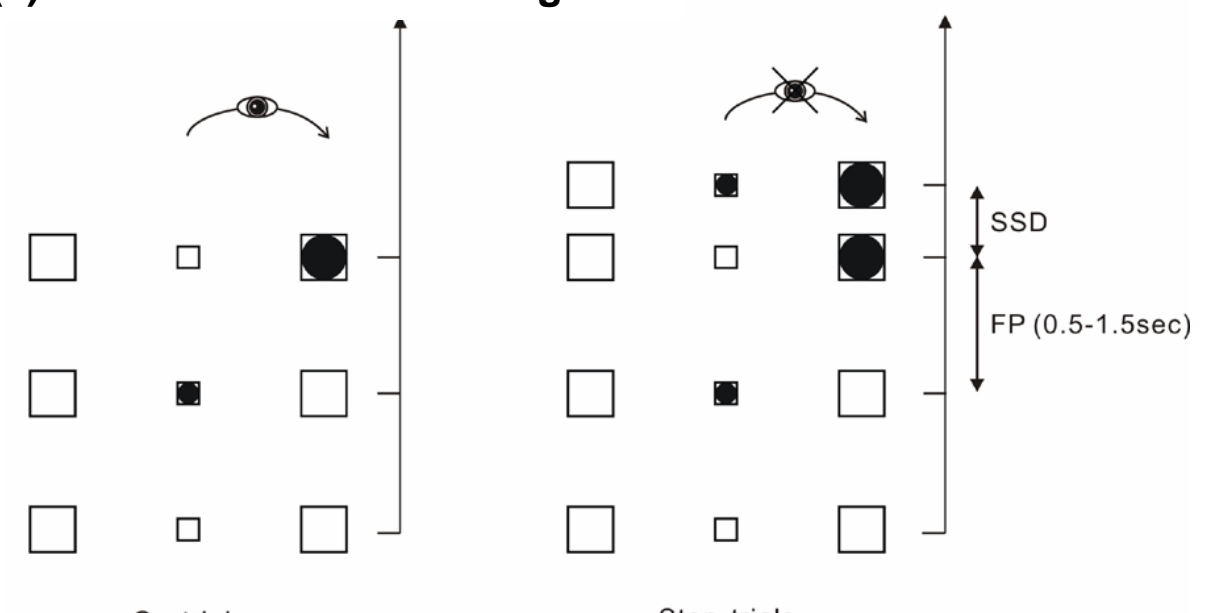

Stop trials

\section{(b) anti-saccade task}

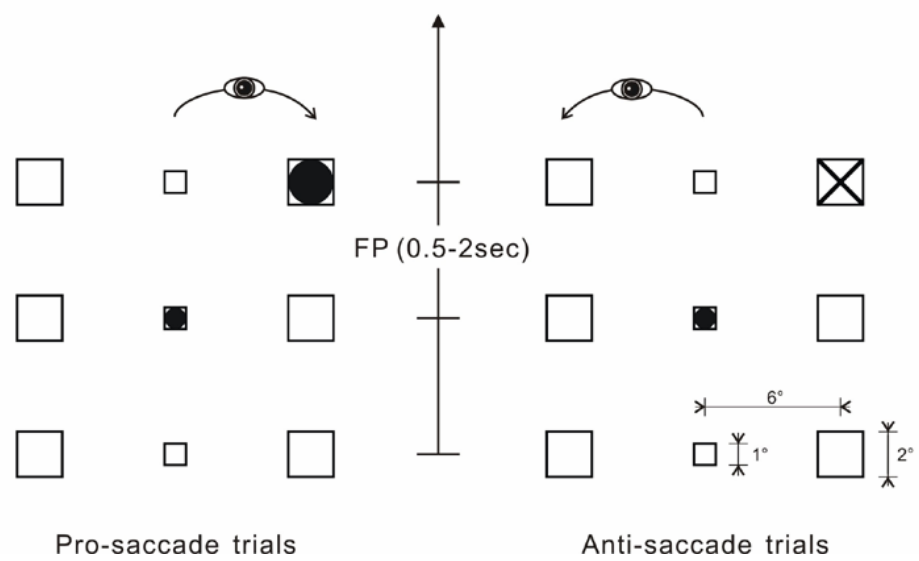

Fig. (1). Behavioral tasks. All stimuli were presented in white against a dark background; arrow indicates the direction of time (a) saccade countermanding task; a fixation point appeared at the center square at the beginning of a trial. In a go trial, a peripheral target appeared at the right or the left square after a fore-period (FP) that varied randomly between 0.5 and 1.5 seconds at the same time when the center fixation disappeared, and the subject was to make a saccade to acquire the target within $750 \mathrm{~ms}$. In a stop trial, the fixation point re-appeared in the center square after a stop signal delay (SSD) following the appearance of the peripheral target, instructing the subjects to hold their fixation at the center square. The SSD was updated from one stop trial to another following a staircase procedure (see text). (b) anti-saccade task; a fixation point appeared at the center square at the beginning of a trial. In a pro-saccade trial, a peripheral target appeared after a fore-period (FP) that varied randomly between 0.5 and 2 seconds at the same time when the center fixation disappeared, and the subject was to make a saccade to acquire the target within $750 \mathrm{~ms}$. In an anti-saccade trial, an "X" appeared at the periphery, instructing the subjects to make a saccade in the opposite direction (time window $=1,500 \mathrm{~ms}$ ).

\section{Data Analysis}

\section{Oculomotor SST}

We computed for each individual subject a critical stopsignal delay (SSD) which represents the time delay between the go and the stop signal in order for the subjects to succeed in half of the stop trials [12]. The stop-signal reaction time (SSRT) was then computed by subtracting the critical SSD from the median go trial RT [10]. We computed the foreperiod $(\mathrm{FP})$ effect: FP effect $=$ median saccade $\mathrm{RT}$ of go trials with FP $<1 \mathrm{sec}-$ median saccade RT of go trials with FP $\geq 1 \mathrm{sec}$; and the post-error slowing (PES) effect: PES effect $=$ median saccade RT of go trials following a failed stop trial - median saccade RT of go trials that did not follow a stop trial (irrespective of target location). Note that in our previous study we computed the post-signal slowing (PSS) effect to index the extent to which subjects were engaged in performance monitoring (PSS effect = median saccade $\mathrm{RT}$ of go trials that followed a stop trial - median saccade RT of go trials that did not follow a stop trial). Since the PES and PSS effects were highly correlated (Pearson $r=0.875, \mathrm{P}<0.001$ for the oculomotor SST; Pearson $r=0.668, \mathrm{P}<0.001$ for the anti-saccade task, see next section), we focused here only on the PES effect (see, however, [35] for an exception). We examined for a correlation each between the FP effect and SSRT and between the PES effect and the SSRT across all subjects with linear regression.

\section{Anti-Saccade Task}

Two outcome measures were derived: error rate of antisaccades and the increase in the RT of anti-saccades, compared to pro-saccades. The increase in anti-saccade RT or 
"anti-saccade RT gain" may be considered as the cost in information processing as resulting from a partial error $[36,37]$. Failure to execute a saccade or saccades that failed to land within the target box in the anti-saccade trials were counted as a directional error. The anti-saccade RT gain was computed by subtracting the mean RT of pro-saccades from the mean RT of anti-saccades, separately for rightward and leftward saccades. An average RT gain was then computed by weighting the proportion of leftward and rightward saccades (Appendix). The same weighting was also employed in the computation of FP and PES effects. We likewise examined for a correlation between the FP effect and antisaccade error rate, between the FP effect and anti-saccade RT gain, between the PES effect and anti-saccade error rate, and between the PES effect and anti-saccade RT gain, by performing a linear regression in each case. Given these multiple tests, the results were evaluated at an $\alpha$ of 0.0125 .

\section{RESULTS}

\section{Oculomotor SST}

Four subjects succeeded in less than $45 \%$ of the stop trials and were excluded from further analysis. The remaining data set consisted of 36 subjects. Table 1a shows their general performance. Subjects succeeded in an average of $98 \%$ of go trials and in $51 \%$ of the stop trials, suggesting the ade-

(a)

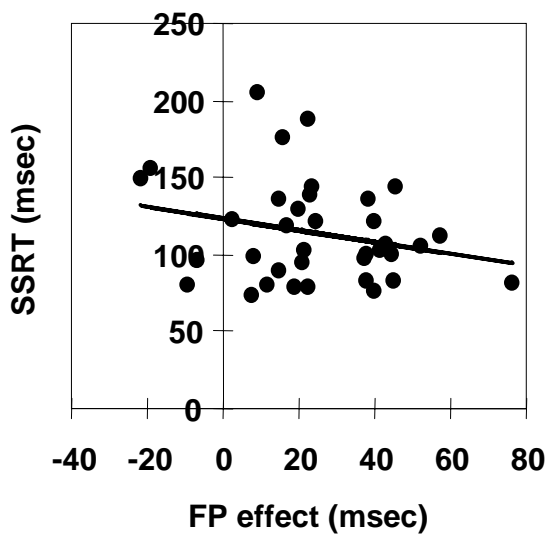

quacy of the staircase procedure in tracking their performance. The stop signal reaction time (SSRT) was computed on the basis of the race model [10]. The mean SSRT was 114 $\mathrm{ms}$, in the range of those values reported in previous studies using oculomotor countermanding tasks [32, 38-42]. All but four subjects demonstrated a positive FP effect and all subjects demonstrated a positive PES effect. We assessed for an association across subjects each between SSRT and the FP effect and between SSRT and the PES effect. Linear regression showed that neither the correlation between the SSRT and the FP effect ( $p=0.152$, Pearson $r=-0.244$, Fig. 2a) nor the correlation the SSRT and the PES effect $(p=0.617$, Pearson $r=0.086$, Fig. 2b) was significant.

\section{Anti-Saccade Task}

One subject did not finish the task, so the data set consisted of 60 subjects (Table 1b). The subjects showed an average $2.0 \pm 15.0 \%$ of fixation failures during the foreperiod, indicating excellent compliance of the subjects to task instructions. They made a directional error in an average of $38 \%$ of the anti-saccade trials, and these directional errors were almost always followed by a corrective eye movement (data not shown). All but 8 subjects showed a positive FP effect, and all but 3 subjects showed a positive PES effect. Anti-saccade performance was assessed with directional error rate and the anti-saccade RT gain (see Methods). Simi-

(b)

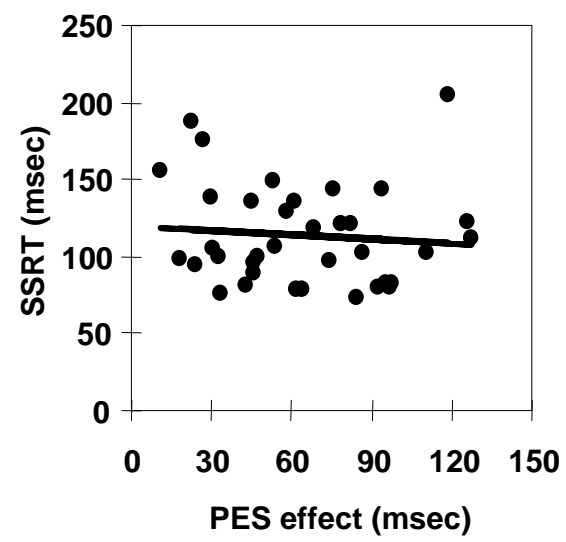

Fig. (2). Countermanding performance. The stop signal reaction time (SSRT) did not correlate with the fore-period (FP) effect (a) or with the PES effect (b). See text for statistics

Table 1. Performance in the Saccade Countermanding (a) and Anti-Saccade (b) Task

\begin{tabular}{|c|c|c|c|c|c|c|c|}
\hline $\begin{array}{l}\text { Go Trial } \\
(\text { succ \%) }\end{array}$ & $\begin{array}{l}\text { Stop Trial } \\
\text { (succ \%) }\end{array}$ & $\begin{array}{c}\text { Fixation Error } \\
\#)\end{array}$ & $\begin{array}{c}\text { Mean Go } \\
\text { RT (ms) }\end{array}$ & $\begin{array}{l}\text { Median Go } \\
\text { RT (ms) }\end{array}$ & $\begin{array}{c}\text { SSRT } \\
(\mathrm{ms})\end{array}$ & $\begin{array}{c}\text { FP Effect } \\
(\mathrm{ms})\end{array}$ & $\begin{array}{c}\text { PES Effect } \\
(\mathrm{ms})\end{array}$ \\
\hline $98.0 \pm 1.2$ & $51.2 \pm 3.0$ & $2 \pm 3$ & $341 \pm 78$ & $330 \pm 93$ & $114 \pm 33$ & $24 \pm 21$ & $64 \pm 32$ \\
\hline \multicolumn{8}{|c|}{ (b) anti-saccade task } \\
\hline $245 \pm 46$ & \multicolumn{2}{|c|}{$333 \pm 80$} & $88 \pm 61$ & $38 \pm 21$ & \multicolumn{2}{|c|}{$12 \pm 13$} & $24 \pm 19$ \\
\hline
\end{tabular}

Note: mean \pm s.d. across subjects; RT = reaction time; SSRT = stop signal reaction time; FP = fore-period; PES = post-error slowing; succ=success. 
larly, we examined for an association between these performance indices and the FP and PES effects across subjects. The results of linear regression showed a marginally significant inverse correlation between the anti-saccade RT gain and the FP effect $(p=0.012$, Pearson $r=-0.32$, Fig. 3b). Antisaccade error did not correlate with FP effect $(\mathrm{p}=0.158$, Fig. 3a). Neither anti-saccade error rate nor RT gain correlated with the PES effect $(p=0.396$ and $p=0.066$, respectively; Fig. $\mathbf{3 c}$ and $\mathbf{3 d}$ ).

Apart from linear correlation, we employed another approach to examine whether response readiness was indeed inversely associated with anti-saccade RT gain in the antisaccade task. Thus, we compared across all 60 subjects the error rate and RT gain between anti-saccade trials when the FP was short $(\mathrm{FP}<1.25 \mathrm{~s}$; FP1) and when the FP was long $(\mathrm{FP} \geq 1.25 \mathrm{~s} ; \mathrm{FP} 2)$. The result showed no difference in the error rate between trials with FP1 $(37 \pm 21 \%)$ and those with FP2 $(38 \pm 21 \%)$. However, the RT gain was indeed significantly greater when the FP was short (RT gain $=95 \pm 63 \mathrm{~ms}$ ) than when the FP was long (RT gain = $82 \pm 63 \mathrm{~ms}$, $\mathrm{t}_{59}=3.113, \mathrm{p}=0.003$; paired $\mathrm{t}$ test $)$.

\section{DISCUSSION}

\section{Fore-Period (FP) Effect and Response Inhibition}

The current results come in striking contrast to what we have hypothesized. In the oculomotor SST, the SSRT did not correlate with the FP effect, and in the anti-saccade task,
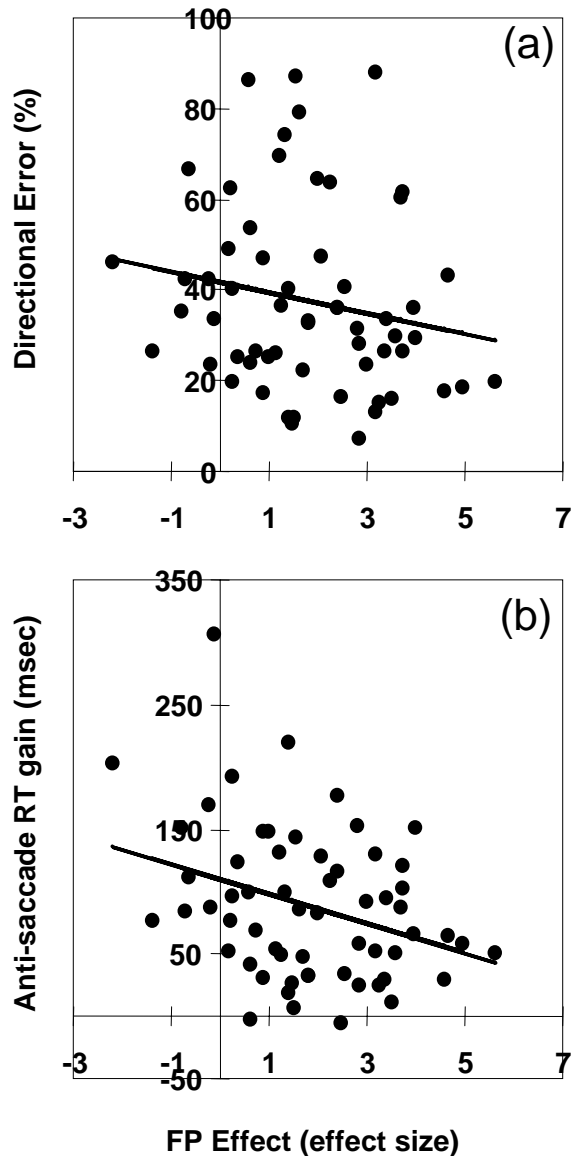

anti-saccade RT gain correlated inversely with the FP effect, though only with marginal significance. The latter result suggests greater response readiness during FP2, as compared to FP1, is associated with less processing cost during execution of an anti-saccade. Therefore, whereas greater response readiness as indexed by the FP effect is associated with decreased inhibitory control in the manual SST, it is associated with greater inhibitory control in the anti-saccade task. What might account for this discrepancy?

One possibility is that, in the manual SST employed in our previous study, the visual stimuli always appeared at the center of fixation [17, 25-27]. Therefore, a greater FP effect may reflect processing advantage conferred to the go signal, which takes temporal precedence to the stop signal. On the other hand, in the current, oculomotor SST, the imperative stimulus or the "go" signal appears at either side of the fixation while the "stop" signal appeared exactly at the center fixation. Therefore, stop signal processing may have been expedited via a foveal attention effect, with greater advantage conferred later during the fore-period when attention is better engaged at the fixation. Thus, although subjects are better prepared to make an eye movement during the second half of the fore-period, this advantage does not compromise the processing of the stop signal, as is the case in the manual SST. In fact, the spotlight theory of visual attention would predict spatial averaging of attention allocation and enhanced processing of visual stimuli at the center fixation $[43,44]$. The fixation cells of the superior colliculus may also play a
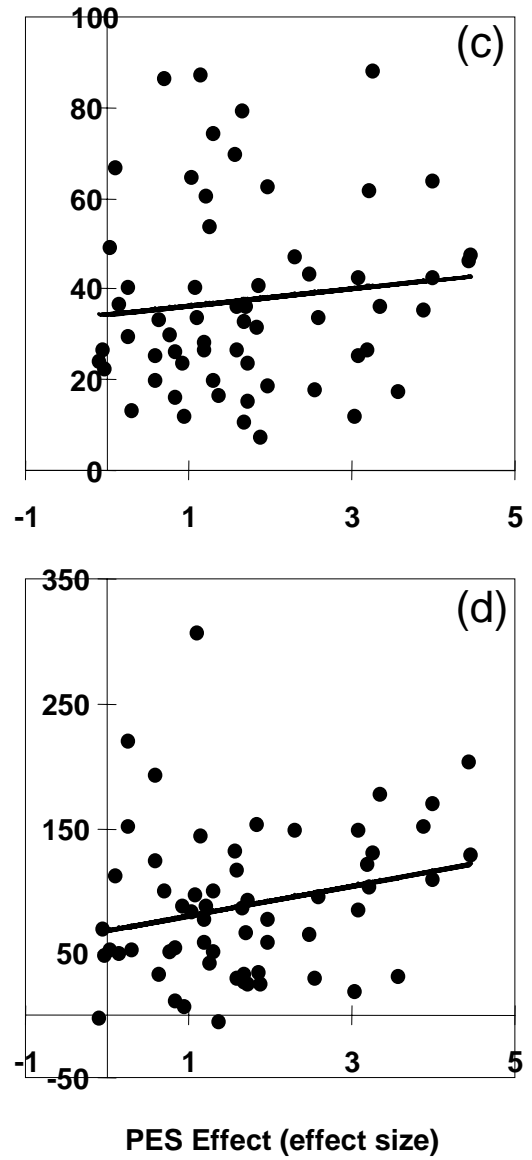

Fig. (3). Anti-saccade performance. (a) The directional error did not significantly correlate with the fore-period (FP) effect. (b) The reaction time (RT) gain of anti-saccades trials showed a marginally significant, weak, inverse correlation with the FP effect. Neither directional error (c) nor RT gain (d) correlated significantly with the PES effect. See text for statistics. 
role in facilitating the effects of the stop signal in "arresting" saccades [4].

A previous study examined the effect of partial information (by varying the probability of go versus no-go signal) on lateralized readiness potential (LRP) during a choice reaction time go/no-go task, with the visual stimuli presented at visual fixation [45]. Greater LRP was found to be associated with blocks of trials with higher go probability. Moreover, more commission errors were made in these blocks with higher go probability. Therefore, greater readiness to respond to an imperative stimulus appears to be associated with poor response inhibition, a finding consistent with our earlier results in the manual task but at odds with our current finding [26]. On the other hand, a recent study manipulated response readiness by cueing subjects of an imminent onset of a no-go signal during a choice RT go/no-go task [46]. The visual stimuli were presented at center fixation. They found that nogo signal processing was delayed, instead of expedited, during episodes of decreased response readiness. This result is thus consistent with our present findings but at odds with those we reported in the manual SST [26]. The authors suggested that reduced response readiness might give rise to more forceful responses that were more difficult to inhibit. Alternatively, we have suggested that in van den Wildenberg et al., 2002 subjects might have adopted a conservative response strategy during episodes preceded by a no-go signal cue such that their general motivation level or vigilant attention imparted disadvantage not only upon go but also no-go signal processing, resulting in prolonged RT and SSRT [26]. Overall, these disparate results indicate that multiple psychological processes may have been subsumed under the rubric of "response readiness" and that the effect of response readiness on stop signal and anti-saccade performance can vary depending on specific stimulus conditions and task requirements.

Several other factors may also complicate how FP effect influences task performance. Response readiness during the fore-period does not necessarily increase linearly with the preparation time; namely, the FP effect may not be linear with respect to the duration of the fore-period $[47,48]$. For instance, in an fMRI study where we varied the fore-period between 1 and 5 seconds in a manual SST, we did not observe an association between the FP effect (similarly defined by dividing the fore-period into 2 time periods of equal duration) with stop signal performance [25]. Thus, although the majority of our subjects demonstrated a positive FP effect, the FP effect as computed may not have captured the same psychological state as we have intended. Indeed, in the current study, 16 of the 36 subjects showed a linear FP effect $(\mathrm{p}<0.05$, RT linearly and inversely correlated with FP duration across all go trials within an individual subject) during the oculomotor SST. Importantly, there was a trend that the SSRT is inversely correlated with the FP effect across these 16 subjects $(p<0.07)$. That is, linear response readiness within the FP between 0.5 and $1.5 \mathrm{~s}$ is associated with decreased SSRT during saccade countermanding. Thus, a linear trend in motor preparation seems to confer certain advantage upon stop signal processing, a result in accord with the current findings from the anti-saccade task. Finally, we have observed a robust $\mathrm{FP}$ effect in a recent study examining response inhibition in children with Tourette's Disorder (mean age $=12$ years, [17]). However, neither children with Tourette's Disorder nor their age-matched healthy controls demonstrated a significant association between the FP effect and their countermanding performance (SSRT). Taken together, we feel that the FP effect remains an important taskrelated variable to compute in order to account for the effect of motor preparation on countermanding performance. However, studies are required to systematically explore the temporal dynamics of this readiness effect, to separate the readiness effect specific to the imperative stimulus from one that perhaps is more general and depends to a greater extent on a subject's vigilant attention or motivation, and to investigate how this effect is modulated by age.

\section{Post-Error Slowing (PES) Effect and Response Inhibition}

We obtained a positive PES effect in both the oculomotor SST and anti-saccade task, providing further evidence for performance monitoring in these cognitive-motor paradigms. However, in neither task does the PES effect correlate significantly with outcome measures, consistent with a earlier report on error monitoring deficits in children with attention deficit hyperactivity disorder [49]. This result stands in contrast with our previous studies where we observed an inverse correlation between the PES effect and the SSRT across different samples of subjects, an association suggesting that greater performance monitoring improves countermanding performance [25,27]. It is worth noting that both the mean (pro-) saccade RT in the anti-saccade (ca. $250 \mathrm{~ms}$ ) and the countermanding (ca. $340 \mathrm{~ms}$ ) task are substantially shorter than the manual RT (ca. $500 \mathrm{~ms}$ ) obtained in the previous studies. Moreover, the SSRT (ca.114 ms) obtained in the current oculomotor SST is also shorter than the SSRT (ca. $200 \mathrm{~ms}$ ) obtained from the simple manual reaction time task in our previous studies [17, 25-27]. Thus, both the "agonistic" and "antagonistic" processes are completed within a significantly shorter duration in the oculomotor than manual task [39]. The speeded sensorimotor transformation that occurs during the execution of a saccadic eye movement is probably less "penetrable" by higher-level cognitive processes, as compared to the execution of the manual response.

In an anti-saccade task, participants are often not aware of their directional error when they are inquired immediately after a trial, although these errors are almost always followed by a corrective eye movement [50,51]. Electrophysiological studies have generally identified two components of eventrelated brain potentials (ERP) associated with a response error [51,52]. The error-related negativity (Ne/ERN) peaks around $80 \mathrm{~ms}$ after an incorrect response and has a frontocentral distribution, whereas the error-related positivity $(\mathrm{Pe})$ is a slower ERP which often follows the Ne/ERN and has a centroparietal distribution. The Ne/ERN and Pe are thought to reflect the operation of an internal/sub-conscious and a peripherally driven/conscious error monitoring mechanism. Nieuwenhuis et al., 2001 found a greater Pe during perceived than unperceived errors, while the Ne/ERN remained indistinguishable, providing evidence for two distinct error monitoring mechanisms. Importantly, they observed that the perceived but not unperceived errors were associated with post-error slowing [51]. Since all but 3 of our 60 subjects showed a positive PES effect in the current study, our subjects seemed to be aware of their error during the anti- 


\section{Appendix}

First, we grouped all pro-saccade trials with respect to their saccade direction (rightward or R and leftward or L) and fore-period (FP1: < $1.25 \mathrm{sec}$ and FP2: $\geq 1.25 \mathrm{sec}$ ). Assume there were $\mathrm{N}_{\mathrm{FP} 1, \mathrm{R}}$ saccades with a mean $\mathrm{RT}$ of $\mathrm{RT}_{\mathrm{FP} 1, \mathrm{R}}$, $\mathrm{N}_{\mathrm{FP} 1, \mathrm{~L}}$ saccades with a mean RT of $\mathrm{RT}_{\mathrm{FP} 1, \mathrm{~L}}, \mathrm{~N}_{\mathrm{FP} 2, \mathrm{R}}$ saccades with a mean RT of $\mathrm{RT}_{\mathrm{FP} 2, \mathrm{R}}, \mathrm{N}_{\mathrm{FP} 2, \mathrm{~L}}$ saccades with a mean RT of RT $\mathrm{FP} 2, \mathrm{~L}_{\text {. Let }} \mathrm{N}_{\text {pro-sacc }}=\mathrm{N}_{\mathrm{FP} 1, \mathrm{R}}+\mathrm{N}_{\mathrm{FP} 2, \mathrm{R}}+$

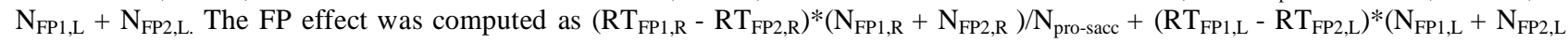
)$/ \mathrm{N}_{\text {pro-sacc. }}$ Second, we grouped all pro-saccade trials according to their direction and whether they followed a pro-saccade or failed anti-saccade. Let $\mathrm{RT}_{\mathrm{Pro}, \mathrm{R}}, \mathrm{RT}_{\mathrm{Pro}, \mathrm{L}}, \mathrm{RT}_{\mathrm{Anti}, \mathrm{R}}, \mathrm{RT}_{\mathrm{Anti}, \mathrm{L}}$ be the mean $\mathrm{RT}$ of rightward pro-saccades preceded by a pro-saccade, of leftward pro-saccades preceded by a pro-saccade, of rightward pro-saccade preceded by a failed anti-saccade, and of leftward pro-saccade preceded by an failed anti-saccade, respectively. Moreover, let $\mathrm{N}_{\text {Pro, } \mathrm{R}}, \mathrm{N}_{\text {Pro, },}, \mathrm{N}_{\mathrm{Anti}, \mathrm{R}}, \mathrm{N}_{\mathrm{Anti}, \mathrm{L}}$ be the number of trials for each of these

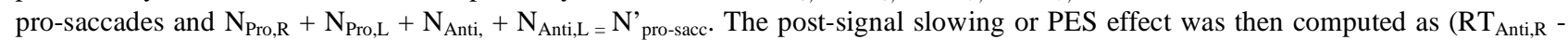
$\left.\mathrm{RT}_{\text {Pro }, \mathrm{R}}\right) *\left(\mathrm{~N}_{\text {Pro, } \mathrm{R}}+\mathrm{N}_{\text {Anti,R }}\right) / \mathrm{N}_{\text {pro-sacc }}^{\prime}+\left(\mathrm{RT}_{\text {Anti, } \mathrm{L}}-\mathrm{RT}_{\text {Pro }, \mathrm{L}}\right) *\left(\mathrm{~N}_{\text {Pro }, \mathrm{L}}+\mathrm{N}_{\text {Anti,L }}\right) / \mathrm{N}_{\text {pro-sacc. }}^{\prime}$

saccade task. The latter rules out the possibility that our subjects simply did not attempt to better their countermanding performance because they were not aware of their errors.

An alternative possibility concerns the stimulus configuration we have employed in the current study. Our subjects were "slowing down" after committing an error and to slow down, they would have to attend less to where the imperative stimulus appeared. Since the target stimuli directing a prosaccade and anti-saccade appeared with similar timing and at the same spatial locations, subjects would have paid less attention to the anti-saccade target, too. These attentional processes could have complicated the relationship between PES effect and anti-saccade performance.

In summary, along with our earlier work we have demonstrated that the effects of motor preparation and error monitoring on response inhibition can vary between manual and oculomotor tasks and with spatial and temporal stimulus configurations. Future studies can perhaps take advantage of these differences in order to understand how motor acts are initiated and suppressed. In particular, a formal model incorporating response readiness and error monitoring could provide a didactic tool for making predictions about countermanding performance in a broader, cognitive context $[5,53$ 55].

\section{ACKNOWLEDGEMENTS}

This study was funded by a research grant from the Chang Gung Memorial Hospital. Chiang-shan Ray Li is currently supported by the Yale Interdisciplinary Women's Health Research Scholar Program on Women and Drug Abuse, funded by the NIH Office of Research on Women's Health and the National Institute on Drug Abuse. Yuan-Chi Tseng is currently supported by an Overseas Scholar Award from the University of Manchester.

\section{REFERENCES}

[1] Hallet PE. Primary and secondary saccades to goals defined by instructions. Vision Res 1978; 8: 1279-1296.

[2] Hanes DP, Schall JD. Countermanding saccades in macaque. Vis Neurosci 1995; 12: 929-937.

[3] Everling S, Fischer B. The antisaccade: a review of basic research and clinical studies. Neuropsychologia 1998; 36: 885-899.

[4] Munoz DP, Everling S. Look away: the anti-saccade task and the voluntary control of eye movement. Nat Rev Neurosci 2004; 5: 218-228.

[5] Schall JD, Boucher L. Executive control of gaze by the frontal lobes. Cogn Affect Behav Neurosci 2007; 7: 396-412.
[6] Hutton SB, Ettinger U. The antisaccade task as a research tool in psychopathology: a critical review. Psychophysiol 2006; 43: 302313.

[7] Milea D, Lehericy S, Rivaud-Pechoux S, Duffau H, Lobel E, Capelle L, Marsault C, Berthoz A, Pierrot-Deseilligny C. Antisaccade deficit after anterior cingulate cortex resection. Neuroreport 2003; 14: 283-287.

[8] Pierrot-Deseilligny C, Muri RM, Ploner CJ, Gaymard B, Demeret S, Rivaud-Pechoux S. Decisional role of the dorsolateral prefrontal cortex in ocular motor behaviour. Brain 2003; 126: 1460-1473.

[9] Ploner CJ, Gaymard BM, Rivaud-Pechoux S, Pierrot-Deseilligny C. The prefrontal substrate of reflexive saccade inhibition in humans. Biol Psychiat 2005; 57: 1159-1165.

[10] Logan GD. On the Ability to Inhibit Thought and Action: An User's Guide to the Stop Signal Paradigm. In: Inhibitory Processes in Attention, Memory and Language (eds. Dagenbach D. \& Carr TH.) pp. 189-239, 1994, Academic Press, San Diego.

[11] Logan GD, Cowan WB. On the ability to inhibit thought and action: A theory of an act of control. Psychol Rev 1984; 91: 295-327.

[12] Levitt H. Transformed up-down methods in psychoacoustics. J Acoust Soc Am 1970; 49: 467-477.

[13] Armstrong IT, Munoz DP. Inhibitory control of eye movements during oculomotor countermanding in adults with attention-deficit hyperactivity disorder. Exp Brain Res 2003; 152: 444-452.

[14] Dimitrov M, Nakic M, Elpern-Waxman J, Granetz J, O'Grady J, Phipps M, Milne E, Logan GD, Hasher L, Grafman J. Inhibitory attentional control in patients with frontal lobe damage. Brain Cognit 2003; 52: 258-270.

[15] Dimoska A, Johnstone SJ, Barry RJ, Clarke AR. Inhibitory motor control in children with attention-deficit/hyperactivity disorder: event-related potentials in the stop-signal paradigm. Biol Psychiatry $2003 ; 54: 1345-1354$.

[16] Fillmore MT, Rush CR. Impaired inhibitory control of behavior in chronic cocaine users. Drug Alcohol Depend 2002; 66:265-73.

[17] Li C-SR, Chang H-L, Hsu Y-P, Wang H-S, Ko N-C. Motor response inhibition in children with Tourette's Disorder. J Neuropsychiatr Clin Neurosci 2006; 18: 417-419.

[18] Monterosso JR, Aron AR, Cordova X, Xu J, London ED. Deficits in response inhibition associated with chronic methamphetamine abuse. Drug Alcohol Depend 2005; 79:273-277.

[19] Oosterlaan J, Sergeant JA. Inhibition in ADHD, aggressive, and anxious children: a biologically based model of child psychopathology. J Abnorm Child Psychol 1996; 24:19-36.

[20] Overtoom CC, Kenemans JL, Verbaten MN, Kemner C, van der Molen MW, van Engeland H, Buitelaar JK, Koelega HS. Inhibition in children with attention-deficit/hyperactivity disorder: a psychophysiological study of the stop task. Biol Psychiatry 2002; 51:66876.

[21] Rieger M, Gauggel S, Burmeister K. Inhibition of ongoing responses following frontal, nonfrontal, and basal ganglia lesions. Neuropsychology 2003; 17: 272-282.

[22] Rubia K, Oosterlaan J, Sergeant JA, Brandeis D, von Leeuwen T. Inhibitory dysfunction in hyperactive boys. Behav Brain Res 1998; 94: 25-32.

[23] Schachar R, Mota VL, Logan GD, Tannock R, Klim P. Deficient inhibitory control in attention deficit hyperactivity disorder. J Abnorm Child Psychol 1995; 23: 411-437. 
[24] Stewart JA, Tannock R. Inhibitory control differences following mild head injury. Brain Cognit 1999; 41: 411-416.

[25] Li C-SR, Huang C, Constable T, Sinha R. Imaging response inhibition in a stop signal task - neural correlates independent of signal monitoring and post-response processing. J Neurosci 2006; 26, 186-192.

[26] Li C-SR, Mathalon DH, Krystal JH. Fore-period effect and stop signal processing time. Exp Brain Res 2005; 167: 305-309.

[27] Li C-SR, Milivojevic V, Kemp K, Kong K, Sinha R. Performance monitoring and stop signal inhibition in abstinent patients with cocaine dependence. Drug Alcohol Depend 2006; 85: 205-212.

[28] Bertelson P, Tisseyre F. The time-course of preparation with regular and irregular foreperiods. Quat J Exp Psychol 1968; 20: 297300.

[29] Rabbit PMA. Errors and error correction in choice-response tasks. J Exp Psychol 1966; 71: 264-272.

[30] Woodrow H. The measurement of attention. Psychol Monogr 1914; 17: $1-158$.

[31] Cabel DW, Armstrong IT, Reingold E, Munoz DP. Control of saccade initiation in a countermanding task using visual and auditory stop signals. Exp Brain Res 2000; 133: 431-441.

[32] Hanes DP, Carpenter RH. Countermanding saccades in humans. Vision Res 1999; 39: 2777-2791.

[33] Schall JD, Stuphorn V, Brown JW. Monitoring and control of action by the frontal lobes. Neuron 2002; 36: 309-322.

[34] Tseng Y-C, Li C-SR. Oculomotor correlates of context-guided learning in visual search. Percept Psychophys 2004; 66: 1363-1378.

[35] Emeric EE, Brown JW, Boucher L, Carpenter RH, Hanes DP, Harris R, Logan GD, Mashru RN, Paré M, Pouget P, Stuphorn V, Taylor TL, Schall JD. Influence of history on saccade countermanding performance in humans and macaque monkeys. Vision Res 2007; 47: 35-49.

[36] Allain S, Carbonnell L, Burle B, Hasbroucq T, Vidal F. On-line executive control: an electromyographic study. Psychophysiology 2004; 41: 113-116.

[37] Coles MG., Scheffers MK, Fournier L. Where did you go wrong? Errors, partial errors, and the nature of human information processing. Acta Psychologia (Amst) 1995; 90: 129-144.

[38] Asrress KN, Carpenter RH. Saccadic countermanding: a comparison of central and peripheral stop signals. Vision Res 2001; 41: 2645-2651.

[39] Boucher L, Stuphorn V, Logan GD, Schall JD, Palmeri TJ. Boucher L, Stuphorn V, Logan GD, Schall JD, Palmeri TJ. Percept Psychophys 2007; 69: 785-801.
[40] Colonius H, Ozyurt J, Arndt PA. Countermanding saccades with auditory stop signals: testing the race model. Vision Res 2001; 41: 1951-1968.

[41] Logan GD, Irwin DE. Don't look! Don't touch! Inhibitory control of eye and hand movements. Psychon Bull Rev 2000; 7: 107-112.

[42] Özyurt J, Colonius H, Arndt PA. Countermanding saccades: evidence against independent processing of go and stop signals. Percept Psychophys 2003; 65: 420-428.

[43] Eriksen CW, St James JD. Visual attention within and around the field of focal attention: a zoom lens model. Percept Psychophys 1986; 40: 225-240.

[44] Posner MI, Snyder CR, Davidson BJ. Attention and the detection of signals J Exp Psychol 1980; 109: 160-174.

[45] Low KA, Miller J. The usefulness of partial information: effects of go probability in the choice/Nogo task. Psychophysiology. 1999; 36: 288-297.

[46] van den Wildenberg WP, van der Molen MW, Logan GD. Reduced response readiness delays stop signal inhibition. Acta Psychologia (Amst). 2002; 111: 155-169.

[47] Karlin L. Reaction time as a function of fore-period duration and variability. J Exp Psychol 1959; 58: 185-191.

[48] Näätänen R. Non-aging fore-periods and simple reaction time. Acta Psychologia 1971; 35: 316-327.

[49] Schachar RJ, Chen S, Logan G.D, Ornstein TJ, Crosbie J, Ickowicz A, Pakulak A. J Abnorm Child Psychol 2004; 32: 285-293.

[50] Mokler A, Fischer B. The recognition and correction of involuntary prosaccades in an antisaccade task. javascript:AL_get(this, 'jour', 'Exp Brain Res.');Exp Brain Res 1999; 125: 511-516.

[51] Nieuwenhuis S, Ridderinkhof KR, Blom J, Band GP, Kok A. Error-related brain potentials are differentially related to awareness of response errors: evidence from an antisaccade task. Psychophysiology $2001 ; 38,752-760$.

[52] Falkenstein M, Hoormann J, Christ S, Hohnsbein J. ERP components on reaction errors and their functional significance: a tutorial. Biol Psychol 2000; 51: 87-107.

[53] Botvinick MM, Braver TS, Barch DM, Carter CS, Cohen JD. Conflict monitoring and cognitive control. Psychol Rev 2001; 108: 624-652.

[54] Boucher L, Palmeri TJ, Logan GD, Schall JD. Inhibitory control in mind and brain: an interactive race model of countermanding saccades. Psychol Rev 2007; 114: 376-397.

[55] Yeung N, Cohen JD, Botvinick MM. The neural basis of error detection: conflict monitoring and the error-related negativity. Psychol Rev 2004; 111: 931-959. 